\title{
Molecular markers of antifolate resistance in Plasmodium falciparum isolates from Luanda, Angola
}

\author{
Bianca E Gama ${ }^{1,2}$, Guilhermina AL Pereira-Carvalho, 1,2,3, Florbela Jl Lutucuta Kosi ${ }^{1,2,4}$, \\ Natália K Almeida de Oliveira ${ }^{1,2}$, Filomeno Fortes ${ }^{2,3}$, Philip J Rosenthal ${ }^{5}$, Virgílio E do Rosário ${ }^{2}$, \\ Cláudio Tadeu Daniel-Ribeiro ${ }^{1,2}$ and Maria de Fátima Ferreira-da-Cruz ${ }^{1,2^{*}}$
}

\begin{abstract}
Background: Plasmodium falciparum malaria remains a leading health problem in Africa and its control is seriously challenged by drug resistance. Although resistance to the sulphadoxine-pyrimethamine (SP) is widespread, this combination remains an important component of malaria control programmes as intermittent preventive therapy (IPT) for pregnant women and children. In Angola, resistance patterns have been poorly characterized, and IPT has been employed for pregnant women since 2006. The aim of this study was to assess the prevalence of key antifolate resistance mediating polymorphisms in the pfdhfr and pfdhps genes in P. falciparum samples from Angola.
\end{abstract}

Methods: Plasmodium falciparum samples collected in Luanda, in 2007, were genotyped by amplification and DNA forward and reverse sequencing of the pfdhfr and pfdhps genes.

Results: The most prevalent polymorphisms identified were pfdhfr 108N (100\%), 51। (93\%), 59R (57\%) and pfdhps $437 \mathrm{G}(93 \%)$. Resistance-mediating polymorphisms in pfdhps less commonly observed in West Africa were also identified (540E in 10\%, 581G in 7\% of samples).

Conclusion: This study documents an important prevalence of 4 P. falciparum polymorphisms that predicts an antifolate resistance in Luanda. Further, some samples presented additional mutations associated to high-level resistance. These results suggest that the use of SP for IPT may no longer be warranted in Angola.

\section{Background}

Sub-Saharan countries remain affected by Plasmodium falciparum malaria, with few exceptions. In 2009, there were an estimated 225 million cases of malaria and 781,000 deaths from malaria worldwide, most of them from Africa [1]. As in other parts of this continent, malaria remains a major problem in Angola, where the entire population is at risk of infection. In 2009, $3,726,606$ suspected malaria cases were reported and $1,5734,222$ malaria cases were confirmed by either RDT or microscopy. The number of confirmed outpatient cases remained nearly one million per year in the last

\footnotetext{
* Correspondence: mffcruz@ioc.fiocruz.br

'Laboratory of Malaria Research, Instituto Oswaldo Cruz, Fiocruz, Rio de Janeiro, Brazil

Full list of author information is available at the end of the article
}

four years, whereas inpatient malaria cases and deaths in 2009 decreased by about $31 \%$ and $13 \%$ respectively, compared to the annual average in 2000-2005. However, it is not clear from the available data whether this reflects a true decrease [1].

The control of malaria is seriously challenged by drug resistance. Resistance to the combination antifolate sulphadoxine-pyrimethamine (SP) is widespread, and this drug is no longer recommended for therapy of falciparum malaria [2]. However, SP resistance is at an intermediate level (e.g. parasite populations more tolerant to the drug but still cleared by the treatment) in most of Africa, and the drug remains an important component of malaria control programmes for use as intermittent preventive therapy (IPT) in pregnant women and children [3]. IPT involves periodic administration of full

\section{Biomed Central}


treatment doses of SP, regardless of the presence of parasitaemia [4]. IPT with SP has been efficacious in the prevention of malaria in pregnant women [5] and children [6], although protective regimens have not been optimized, and the impact of different levels of SP resistance on protective efficacy is not well understood [7].

Resistance to SP is mediated by point mutations in genes encoding the target enzymes dihydrofolate reductase $(p f d h f r)$ and dihydropteroate synthetase (pfdhps) $[8,9]$. Increasing numbers of a well-defined set of mutations leads to increasing resistance [10,11]. In Africa, three pfdhfr (51I, 59R, 108N) and two pfdhps (437G, $540 \mathrm{E})$ mutations are common in some areas, and the prevalence of the key polymorphisms, pfdhfr 59R and pfdhps 540E is associated with the treatment efficacy of SP $[12,13]$. The treatment efficacy of SP in IPT remains quite good in parts of west and central Africa, in large part due to the lack of one key polymorphism, pfdhps $540 \mathrm{E}$, in infecting parasites $[14,15]$. Considering differences in prevalence of this key polymorphism across Africa and its importance, the WHO recommends IPT with SP for infants only in areas with a prevalence of pfdhps 540E < 50\% [16]. Since IPT continues to be recommended in pregnancy across Africa, the aim of this study was to assess the prevalence of key antifolate resistance mediating polymorphisms in the capital of Angola, Luanda, where molecular resistance patterns have not been characterized yet, and where SP for pregnancy has been employed since 2006 [17].

\section{Methods}

\section{Study site and population}

Blood samples were collected in 2007 from outpatients attending for malaria diagnosis at four Luanda health facility posts located at the municipalities of Sambizanga, Imgombotas, Cazenga and Viana. Luanda has a population of approximately 4.5 million and is considered mesoendemic for malaria. Malaria is present throughout the year, with a marked increase in incidence after rains that peak during April and May.

Patients diagnosed with falciparum malaria based on Giemsa-stained thick smears were included in this study after informed consent was obtained. Inclusion criteria comprised individuals with age $\geq 12$ years, no clinical evidence of complicated malaria and monoinfection with $P$. falciparum. The study was approved by the National Institute of Public Health/Angola Ethics Research Committee with agreement of the Instituto Oswaldo Cruz/Fiocruz.

\section{Study procedures}

After enrollment, $5 \mathrm{ml}$ of blood was collected by venipuncture and placed into ethylenediaminetetraacetic acid vacutainer tubes (Becton Dickinson). The samples were centrifuged ( $350 \mathrm{~g}, 10$ minutes), and pellets were frozen with an equal volume of cryopreservation solution $(0.9 \%$ sodium chloride, $4.2 \%$ sorbitol and $28 \%$ glycerol). Frozen samples were transported to the Instituto Oswaldo Cruz (Fiocruz), Rio de Janeiro, Brazil for further studies.

\section{DNA preparation}

Blood samples were thawed, and $1 \mathrm{ml}$ was used for DNA extraction with the QIAamp midi kit, as described by the manufacturer (Qiagen). Samples were resuspended in a final volume of $50 \mu \mathrm{l}$.

\section{Nested PCRs for pfdhfr and pfdhps}

The $p f d h f r$ and $p f d h p s$ amplification protocols were as described elsewhere [18]. Briefly, $2 \mu \mathrm{l}$ of DNA solution was added to a $48 \mu \mathrm{l}$ mixture containing $0.25 \mu \mathrm{M}$ primers M1 (5' TTT ATG ATG GAA CAA GTC TGC 3') and M7 (5' CTA GTA TAT ACA TCG CTA ACA 3') for pfdhfr or primers N1 (5' GAT TCT TTT TCA GAT GGA GG $3^{\prime}$ ) and N2 (5' TTC CTC ATG TAA TTC ATC TGA 3') for pfdhps. In the nested PCR, $2 \mu \mathrm{l}$ of the initial PCR product was mixed with $0.25 \mu \mathrm{M}$ primers M3b (5' TGA TGG AAC AAG TCT GCG ACG TT 3') and M9 (5' CTG GAA AAA ATA BCAT CAC ATT CAT ATG 3') for pfdhfr or primers R2 (5' AAC CTA AAC GTG CTG TTC AA 3') and R (5' AAT TGT GTG ATT TGT CCA CAA 3') for pfdhps. The pfdhfr primers amplify a $594 \mathrm{bp}$ fragment comprising the SNPs A16V/ S, C50R, N51I, C59R, S108N, V140L and I164L, and pfdhps primers amplify a 711 bp region containing SNPs S436A/F/C, A437G, K540E, A581G and A613T/S. PCR reactions were run in the GeneAmp PCR System 9700 (Applied Biosystems). Positive (DNA extracted from blood from patients with known P. falciparum infection) and negative (no DNA and DNA extracted from individuals who had never traveled to malaria-endemic areas) controls were also used in each round of amplification.

\section{PCR analysis and product purification}

PCR products were separated by $2 \%$ agarose-gel electrophoresis. Products were purified through the Wizard SV Gel and PCR Clean-Up System (Promega), according to the manufacturer's instructions.

\section{DNA sequencing}

DNA sequencing from forward and reverse strands was performed using $p f d h f r$ or $p f d h p s$ nested PCR primers plus the purified product according to Big Dye ${ }^{\circledR}$ Terminator Cycle Sequencing Ready Reaction version 3.1 instructions (Applied Biosystems). Sequences were read using an ABI PRISM DNA Analyzer 3730 (Applied Biosystems) from the Genomic Platform/PDTIS/Fiocruz [19]. Forward and reverse sequences were analysed 
using the free software Bioedit Sequence Alignment Editor version 7.0.5.2.

\section{Results}

Samples were analysed from 66 patients, aged 21 to 30 years, with a diagnosis of acute uncomplicated falciparum malaria. Parasitaemia ranged from 500 to 100,000 parasites/ $\mu$ l. The $p f d h f r$ analysis yielded 61 sequences and that for $p f d h p s 30$ sequences. The failure to satisfactory amplify pfdhps gene in Angolan samples might be somehow attributed to primer limitations due to unknown polymorphisms in target sequences.

The most prevalent polymorphisms were $p f d h f r 108 \mathrm{~N}$ (100\%), 51I (93\%), 59R (57\%) and pfdhps 437G (93\%) (Table 1). In addition, other polymorphisms were detected, including $50 \mathrm{R}$ in the $p f d h f r$ gene $(6 \%)$ and $540 \mathrm{E}(10 \%)$ and $581 \mathrm{G}(7 \%)$ in the pfdhps gene. No mutations were found at 16, 140 and 164 codons from pfdhfr gene. Considering haplotypes, the most prevalent were CIRN (51\%) and CICN (34\%) for pfdhfr gene (codons 50, 51, 59 and 108), and SGKAA (60\%) and AGKAA (23\%) for pfdhps gene (codons 436, 437, 540, 581 and 613) (Table 2).

Only one sample presented a mixed infection for $p f d h f r$. Wild-type profiles were observed in pfdhps in two samples: one from Sambizanga and one from Imgombotas. No significant difference between the prevalence of the $p f d h f r$ and pfdhps haplotypes was observed among the four municipalities.

\section{Discussion}

This study documents a recent prevalence of $P$. falciparum antifolate resistance mutations in Luanda, the capital of Angola. It shows high levels of resistance-associated polymorphisms in the genes encoding the antifolate target enzymes $p f d h f r$ and $p f d h p s$, with most parasites containing 4 mutations that have been associated with an intermediate level of resistance, and 7\% of them additionally containing pfdhps 540E and 581G, both of which are associated with a higher level of resistance $[10,20]$. These molecular profiles are indicative of unsatisfactory response

Table 1 Pfdhfr and pfdhps SNPs prevalence from $P$. falciparum parasites from Luanda, Angola.

\begin{tabular}{|c|c|c|c|c|c|}
\hline Gene & SNPs & Prevalence (\%) & Gene & SNPs & Prevalence (\%) \\
\hline \multirow{7}{*}{$\begin{array}{l}\text { pfdhfr } \\
(\mathrm{n}=61)\end{array}$} & $16 \mathrm{~V} / \mathrm{S}$ & $0 / 61(0)$ & pfdhps & $436 \mathrm{~A}$ & $7 / 30(23)$ \\
\hline & $50 R$ & $4 / 61(6)$ & & $437 G$ & $2 / 30(93)$ \\
\hline & 511 & $57 / 61$ (93) & & $540 \mathrm{E}$ & $3 / 30(10)$ \\
\hline & $59 R$ & $35 / 61(57)$ & & $581 G$ & $2 / 30(7)$ \\
\hline & $108 \mathrm{~N}$ & $61 / 61(100)$ & & $613 T / S$ & $0 / 30(0)$ \\
\hline & $140 \mathrm{~L}$ & $0 / 61(0)$ & & & \\
\hline & $1164 \mathrm{~L}$ & $0 / 61(0)$ & & & \\
\hline
\end{tabular}

Table 2 Pfdhfr and pfdhps haplotypes of P.falciparum parasites from Luanda, Angola.

\begin{tabular}{|c|c|c|c|c|}
\hline Gene & Haplotypes & $n$ & $\%$ & Mutated codons \\
\hline \multirow{5}{*}{$\begin{array}{c}\text { Pfdhfr } \\
(\mathrm{n}=61)\end{array}$} & CIRN & 31 & 51 & 3 \\
\hline & $\mathrm{CICN}$ & 21 & 34 & 2 \\
\hline & CNRN & 4 & 6 & 2 \\
\hline & $\mathrm{RICN}$ & 4 & 6 & 3 \\
\hline & $\mathrm{CICN} / \mathrm{S}$ & 1 & 2 & 1 or 2 \\
\hline \multirow{5}{*}{$\begin{array}{c}\text { Pfdhps } \\
(\mathrm{n}=30)\end{array}$} & SGKAA & 18 & 60 & 1 \\
\hline & AGKAA & 7 & 23 & 2 \\
\hline & SAKAA & 2 & 7 & 0 \\
\hline & SGEAA & 1 & 3 & 2 \\
\hline & SGEGA & 2 & 7 & 3 \\
\hline
\end{tabular}

Codon positions: pfdhfr C50R, N511, C59R and S108N, pfdhps S436A/F/C, A437G, K540E, A581G and A613T/S. The sensitive haplotype is underlined and the mutated codons are shown in bold characters.

to SP and they are consistent with the results of a clinical trial in central Angola that showed poor antimalarial efficacy of this drug when it was used for treatment of children under five years old with uncomplicated malaria [21] as well as with the data of previous in vivo studies from East African countries [22-24].

The results showed a complex mixture of $p f d h f r /$ pfdhps haplotypes in Luanda as already reported in other six provinces of Angola [25,26]. The 164L mutation was not disclosed, corroborating the findings of other nearby African countries [27-29]. The pfdhfr 50R SNP herein found confers an increased level of resistance to pyrimethamine and this mutation is characteristic from South-American isolates [30] and, it was found only once in Africa, when Kenyan isolates were evaluated [31]. Three polymorphisms that mediate lowlevel resistance to SP, pfdhfr $108 \mathrm{~N}, p f d h f r$ 51I, and pfdhps 437G, were nearly universal and the pfdhfr 59R mutation, which is associated with higher-level resistance, was common. Additional polymorphisms were also seen, notably the pfdhps 540E and 581G mutations presented in the same sample that have been associated with a high-level of SP resistance.

Considering these data, it can be predicted that SP will have inadequate efficacy for the treatment of falciparum malaria, and further that it may no longer be appropriate for IPT in Angola. Indeed, although the number of samples available for study was limited, the prevalence of the pfdhps $540 \mathrm{E}$ mutation might suggest that the cut-off level recently declared by the WHO for abandonment of IPT with SP in infants may be reached in this country. Unfortunately, no other drug offers simple, single-dose IPT. Surveillance works should provide advanced warning of SP failure in Angola. 


\section{Conclusions}

Since SP is still used for IPT in pregnant women as well as to treat bacterial infections, in Angola, a continuous pressure for such mutations selection may limit the therapeutic life span of this combination. Therefore the present data apparently argue against the use of this drug combination in Angola. The data also emphasize the need for a closer screening of these polymorphisms, especially pfdhps 540E, along to the testing of other drugs for chemoprevention of malaria, including IPT in pregnant women and children, as an urgent priority.

\section{Acknowledgements}

We would like to thank the staff from the Genomic Platform/PDTIS/Fiocruz. This work was financially supported by POM/PEF/Instituto Oswaldo Cruz, CNPq/PAPES-Fiocruz, FAPERJ and PRONEX programs from Brazil (CNPq, DECIT and FAPERJ) and by the Ministry of Health and Eduardo Santos Foundation from Angola. PJR is a Distinguished Clinical Scientist of the Doris Duke Charitable Foundation. MFFC and CTDR are recipients of a CNPq Scientist fellowship and are "Cientista do Nosso Estado" from FAPERJ.

\section{Author details \\ ${ }^{1}$ Laboratory of Malaria Research, Instituto Oswaldo Cruz, Fiocruz, Rio de Janeiro, Brazil. ${ }^{2}$ Health Progress and Investigation Network of the Portuguese-Speaking Countries Community (RIDES/CPLP), Centro de Malária e Doenças Tropicais, Instituto de Higiene e Medicina Tropical, Universidade Nova de Lisboa, Lisboa, Portugal. ${ }^{3}$ National Institute of Public Health, Luanda, Angola. ${ }^{4}$ Department of Biology, Universidade Agostinho Neto, Luanda, Angola. ${ }^{5}$ Department of Medicine, San Francisco General Hospital, University of California San Francisco, San Francisco, USA.}

\section{Authors' contributions}

BEG participated in the design of the study, carried out the molecular analysis and drafted the manuscript; GALPC and FJILK were the responsible for blood samples collection; NKAO performed the PCR assays; FF helped in study design and field facilities; PJR and CTDR helped in the design of the study and reviewed the manuscript; MFFC conceived the study, coordinated its design, and finalized the manuscript. All authors have read and approved the final text.

\section{Competing interests}

The authors declare that they have no competing interests.

Received: 9 May 2011 Accepted: 24 August 2011

Published: 24 August 2011

\section{References}

1. WHO: World Malaria Report 2010 [http://www.who.int/malaria/publications/ country-profiles/profile_ago_en.pdf].

2. Talisuna A, Bloland P, D'Alessandro U: History, dynamics, and public health importance of malaria parasite resistance. Clin Microbiol Rev 2004, 17:235-254.

3. Gosling R, Cairns M, Chico R, Chandramohan D: Intermittent preventive treatment against malaria: an update. Expert Rev Anti Infect Ther 2010, 8:589-606

4. Reducing the burden of malaria in pregnancy 2004. [http://www.who.int/ malaria/publications/atoz/merajan2003.pdf].

5. ter Kuile F, van Eijk A, Filler S: Effect of sulfadoxine-pyrimethamine resistance on the efficacy of intermittent preventive therapy for malaria control during pregnancy: a systematic review. JAMA 2007, 297:2603-2616.

6. Aponte J, Schellenberg D, Egan A, Breckenridge A, Carneiro I, Critchley J, Danquah I, Dodoo A, Kobbe R, Lell B, May J, Premji Z, Sanz S, Sevene E, Soulaymani-Becheikh R, Winstanley P, Adjei S, Anemana S,

Chandramohan D, Issifou S, Mockenhaupt F, Owusu-Agyei S, Greenwood B, Grobusch MP, Kremsner PG, Macete E, Mshinda H, Newman RD, Slutsker L,
Tanner M, Alonso P, Menendez C: Efficacy and safety of intermittent preventive treatment with sulfadoxine-pyrimethamine for malaria in African infants: a pooled analysis of six randomised, placebo-controlled trials. Lancet 2009, 374:1533-1542.

7. Parikh S, Rosenthal PJ: Intermittent preventive therapy for malaria in pregnancy: is sulfadoxine-pyrimethamine the right drug? Clin Pharmacol Ther 2010, 87:160-162

8. Cowman A, Morry M, Biggs B, Cross G, Foote S: Amino acid changes linked to pyrimethamine resistance in the dihydrofolate reductasethymidylate synthase gene of Plasmodium falciparum. Proc Natl Acad Sci USA 1988, 85:9109-9113.

9. Brooks D, Wang P, Read M, Watkins W, Sims P, Hyde J: Sequence variation of the hydroxymethyldihydropterin pyrophosphokinase: dihydropteroate synthase gene in lines of the human malaria parasite, Plasmodium falciparum, with differing resistance to sulfadoxine. Eur J Biochem 1994, 224:397-405.

10. Plowe C, Cortese J, Djimde A, Nwanyanwu O, Watkins W, Winstanley P, Estrada-Franco J, Mollinedo R, Avila J, Cespedes J, Carter D, Doumbo OK: Mutations in Plasmodium falciparum dihydrofolate reductase and dihydropteroate synthase and epidemiologic patterns of pyrimethamine-sulfadoxine use and resistance. J Infect Dis 1997, 176:1590-1596.

11. Kublin J, Witzig R, Shankar A, Zurita J, Gilman R, Guarda J, Cortese J, Plowe C: Molecular assays for surveillance of antifolate-resistant malaria. Lancet 1998, 351:1629-1630.

12. Gregson A, Plowe C: Mechanisms of resistance of malaria parasites to antifolates. Pharmacol Rev 2005, 57:117-145.

13. Kublin J, Dzinjalamala F, Kamwendo D, Malkin E, Cortese J, Martino L, Mukadam R, Rogerson S, Lescano A, Molyneux M, Winstanley PA, Chimpeni P, Taylor TE, Plowe CV: Molecular markers for failure of sulfadoxine-pyrimethamine and chlorproguanil-dapsone treatment of Plasmodium falciparum malaria. J Infect Dis 2002, 185:380-388.

14. Pearce R, Pota H, Evehe M, Bâ e-H, Mombo-Ngoma G, Malisa A, Ord R, Inojosa W, Matondo A, Diallo D, Mbacham W, van den Broek IV, Swarthout TD, Getachew A, Dejene S, Grobusch MP, Njie F, Dunyo S, Kweku M, Owusu-Agyei S, Chandramohan D, Bonnet M, Guthmann JP, Clarke S, Barnes KI, Streat E, Katokele ST, Uusiku P, Agboghoroma CO, Elegba OY, Cissé B, A-Elbasit IE, Giha HA, Kachur SP, Lynch C, Rwakimari JB, Chanda P, Hawela M, Sharp B, Naidoo I, Roper C: Multiple origins and regional dispersal of resistant dhps in African Plasmodium falciparum malaria. PLoS Med 2009, 6:e1000055.

15. Dorsey G, Dokomajilar C, Kiggundu M, Staedke SG, Kamya MR, Rosenthal PJ: Principal role of dihydropteroate synthase mutations in mediating resistance to sulfadoxine-pyrimethamine in single-drug and combination therapy of uncomplicated malaria in Uganda. Am J Trop Med Hyg 2004, 71:758-763.

16. WHO Policy recommendation on Intermittent Preventive Treatment during infancy with sulphadoxine-pyrimethamine (SP-IPTi) for Plasmodium falciparum malaria control in Africa. [http://www.who.int/ malaria/news/WHO_policy_recommendation_IPTi_032010.pdf].

17. Malaria Operational Plan, Year Five (FY2010) - Angola. [http://www fightingmalaria.gov/countries/mops/fy10/angola_mop-fy10.pdf].

18. Pearce R, Drakeley C, Chandramohan D, Mosha F, Roper C: Molecular determination of point mutation haplotypes in the dihydrofolate reductase and dihydropteroate synthase of Plasmodium falciparum in three districts of northern Tanzania. Antimicrob Agents Chemother 2003, 47:1347-1354.

19. Otto T, Vasconcellos E, Gomes L, Moreira A, Degrave W, Mendonça-Lima L, Alves-Ferreira M: ChromaPipe: a pipeline for analysis, quality control and management for a DNA sequencing facility. Genet Mol Res 2008, 7:861-871

20. Gesase S, Gosling RD, Hashim R, Ord R, Naidoo I, Madebe R, Mosha JF, Joho A, Mandia V, Mrema H, Mapunda E, Savael Z, Lemnge M, Mosha FW, Greenwood B, Roper C, Chandramohan D: High resistance of Plasmodium falciparum to sulphadoxine/pyrimethamine in northern Tanzania and the emergence of dhps resistance mutation at Codon 581. PLoS One 2009, 4:e4569.

21. Guthmann J, Ampuero J, Fortes F, van Overmeir C, Gaboulaud V Tobback S, Dunand J, Saraiva N, Gillet P, Franco J, Denoncin A, van Herp M, Balkan S, Dujardin JC, D'Alessandro U, Legros D: Antimalarial efficacy of chloroquine, amodiaquine, sulfadoxine-pyrimethamine, and the 
combinations of amodiaquine + artesunate and sulfadoxinepyrimethamine + artesunate in Huambo and Bie provinces, central Angola. Trans R Soc Trop Med Hyg 2005, 99:485-492.

22. Bloland PB: Drug resistance in malaria. World Health Organization, Geneva, 2001 [http://www.who.int/csr/resources/publications/drugresist/malaria.pdf], WHO/CDS/CSR/DRS/2001.4

23. Checchi F, Piola P, Kosack C, Ardizzoni E, Klarkowski D, Kwezi E, Priotto G, Balkan S, Bakyaita N, Brockman A, Guthmann JP: Antimalarial efficacy of sulfadoxine-pyrimethamine, amodiaquine and a combination of chloroquine plus sulfadoxine-pyrimethamine in Bundi Bugyo, western Uganda. Trop Med Int Health 2004, 9:445-450.

24. Stivanello E, Cavailler P, Cassano F, Omar SA, Kariuki D, Mwangi J, Piola P, Guthmann JP: Efficacy of chloroquine, sulphadoxine-pyrimethamine and amodiaquine for treatment of uncomplicated Plasmodium falciparum malaria in Kajo Keji county, Sudan. Trop Med Int Health 2004, 9:975-980.

25. Fortes F, Dimbu R, Figueiredo P, Neto Z, do Rosário VE, Lopes D: Evaluation of prevalence's of pfdhfr and pfdhps mutations in Angola. Malar J 2011, 10:22.

26. Menegon $M$, Pearce $R$, Inojosa W, Pisani V, Abel P, Matondo A, Bisoffi Z, Majori G, Ord R, Warhurst D, Roper C, Severini C: Monitoring for multidrugresistant Plasmodium falciparum isolates and analysis of pyrimethamine resistance evolution in Uige province, Angola. Trop Med Int Health 2009, 14:1251-1257.

27. Fernandes $N$, Figueiredo $P$, do Rosário VE, Cravo P: Analysis of sulphadoxine/pyrimethamine resistance-conferring mutations of Plasmodium falciparum from Mozambique reveals the absence of the dihydrofolate reductase 164L mutant. Malar J 2007, 6:35.

28. Ndounga M, Tahar R, Basco L, Casimiro P, Malonga D, Ntoumi F: Therapeutic efficacy of sulfadoxine-pyrimethamine and the prevalence of molecular markers of resistance in under 5-year olds in Brazzaville, Congo. Trop Med Int Health 2007, 12:1164-1171.

29. Mkulama MA, Chishimba S, Sikalima J, Rouse P, Thuma PE, Mharakurwa S: Escalating Plasmodium falciparum antifolate drug resistance mutations in Macha, rural Zambia. Malar J 2008, 7:87.

30. Cortese JF, Caraballo A, Contreras CE, Plowe CV: Origin and dissemination of Plasmodium falciparum drug-resistance mutations in South America. $J$ Infect Dis 2002, 186:999-1006.

31. McCollum A, Poe A, Hamel M, Huber C, Zhou Z, Shi Y, Ouma P, Vulule J, Bloland P, Slutsker L, Barnwell JW, Udhayakumar V, Escalante AA: Antifolate resistance in Plasmodium falciparum: multiple origins and identification of novel dhfr alleles. J Infect Dis 2006, 194:189-197.

doi:10.1186/1475-2875-10-248

Cite this article as: Gama et al.: Molecular markers of antifolate resistance in Plasmodium falciparum isolates from Luanda, Angola. Malaria Journal 2011 10:248.

\section{Submit your next manuscript to BioMed Central and take full advantage of:}

- Convenient online submission

- Thorough peer review

- No space constraints or color figure charges

- Immediate publication on acceptance

- Inclusion in PubMed, CAS, Scopus and Google Scholar

- Research which is freely available for redistribution

Submit your manuscript at www.biomedcentral.com/submit
Biomed Central 